\title{
Matriksiny in Blood Serum Before and After Surgical Treatment and Its Connection With Protein HER-2/NEU
}

\author{
Dmitrii L. Shek, Olga M. Kuznetsova, Anna Yu. Chibisova \\ People's Friendship University of Russia, Moscow, Russia
}

\begin{abstract}
In this study, we analyzed two things. Firstly, it was the concentration of matrix metalloproteinases (MMPs) $-2,-7$, and -9 in the serum of patients with breast cancer (BC) before and two weeks after the surgical removal of the tumor, and secondly, we analyzed possible connection of MMPs with protein human epidermal growth factor receptor 2 (HER-2/neu). We also set the comparative analysis of the content of MMP-2, MMP-7, and MMP-9 in tumor (BC) tissues and histologically intact tissues, paying attention to the content of sex hormone receptors and the protein HER-2/neu. We found out that there is the existence of a definite connection between the content of MMPs $-2,-7$, and -9 types and tumor's receptor status in BC patients. The content of MMP-7 and MMP-9 was significantly higher in the prognostically unfavorable receptor status. Significantly higher values of MMP-2 and -7 detected in tumor's tissue comparing to histologically intact tissue. We found out that increased concentration of MMP-2 in the tumor was connected with the status of the tumor's receptors $(p<0.05)$. The highest concentrations of MMP-7 and MMP-9 were found in tumors, which were larger than 4.0cm. The lowest initial content of MMP-9 in the serum was found in patients with low-differentiated tumors $(p=0.04)$, high initial concentrations of MMP-2 have been identified in patients with Stage III, which may be clinically unfavorable sign. The results of the research show us that the concentration of metalloproteinases in serum of BC patients determined before surgical treatment, reflects the prevalence of oncological process. We believe that it is necessary to analyze the concentration of MMP in serum and tissues at the same time and also examine the content of endogenous inhibitors in the same patients.
\end{abstract}

Keywords: metalloproteinase, enzyme immunoassay, breast cancer (BC), protein human epidermal growth factor receptor 2 (HER-2/neu), sex hormone receptors

\section{Introduction}

The most important problem in oncology remains metastasis, which is a major morphological characteristic of cancer cells. That is why the study and detalization of the molecular mechanisms, which control this process are the most important prerequisite for the successful struggle for increasing life expectancy and improve the quality of cancer patients. In the structure of malignant lesions, breast cancer (BC) belongs to the first place since 1985. Still remains an urgent problem for early screening, for definition of the each individual's prognosis of metastatic process, and for determination of personalized tactics of treatment. It is known that malignant tumors characterize by invasive growth and the ability to metastasize. One of the main

Dmitrii L. Shek, M.D., Department of Biochemistry, Faculty of Medicine, People's Friendship University of Russia.

Olga M. Kuznetsova, Ph.D., professor, Department of Biochemistry, Faculty of Medicine, People's Friendship University of Russia.

Anna Yu. Chibisova, M.D., Department of Biochemistry, Faculty of Medicine, People's Friendship University of Russia. 
roles in the process of invasion and metastasis certainly play matrix metalloproteinases (matriksiny or MMPs). The degree of tissue remodeling determined by the equilibrium state between MMPs and their endogenous inhibitors. Matriksiny or MMPs are responsible for catalyzing the hydrolysis of almost all major proteins of the extracellular matrix. MMPs make a family of Zn-dependent endopeptidases which significance is currently being actively studied. Actual literature data indicate that high levels of expression of MMP-2 and MMP-9 in the tumor are associated with a low degree of differentiation and progression of adenocarcinoma of the lung, bladder, and ovarian carcinoma. Expression of MMP-7 is detected in epithelial tumors of the gastrointestinal tract, prostate carcinoma, and BC. It proved that MMP expression increases in tumors of various origins, that is why matriksiny now regarded as future biomarkers of prognosis and drug sensitivity of cancer.

In our study, we made comparative analysis of the concentration of MMP-2, MMP-7, and MMP-9 in the serum of patients with $\mathrm{BC}$ before and two weeks after the surgical removal of the tumor, counted the concentration of MMP $-2,-7$, and -9 in the tissues of $\mathrm{BC}$ and histologically intact tissue, and finally, we made the analysis of the results relationship to the main clinical and morphological parameters of the disease, protein human epidermal growth factor receptor 2 (HER-2/neu) and sex hormones receptors.

\section{Materials and Methods}

The study included 45 women with BC in various stages. Their average age was $53.7 \pm 1.6$ years. In $22.2 \%$ of patients detected Stage I, in 53.3\% - Stage II, and 24.4\% - Stage III. All 45 patients did not have distant metastases at the start of treatment. The majority of the examinees established infiltrative ductal histological structure of the BC (80\%), all other types were represented by single cases. We used standard sets for direct immunoassay to quantify the MMP concentration (Quantikine ${ }^{\circledR}, R \&$ D Systems, USA). The concentration of the investigated parameters in tissues was determined in nanograms (ng) per $1 \mathrm{mg}$ of total protein. Protein was determined by the Lowry method. As a control, we used the content of proteins in extracts of histologically intact breast tissue distant from the edge of the tumor at a distance of $3.0 \mathrm{~cm}$. Determination of steroid hormone receptors are performed on paraffin-embedded tumor sections via biotin streptavidin immunoperoxidase method with a monoclonal antibody to the estrogen receptor (ER) and progesterone receptor (PR), made by company Dako (Denmark). Statistical analysis of results was made by the Statistical Package for Social Sciences (SPSS) 9.0 and Statistica 6.0.

\section{Results and Discussion}

Using the enzyme immunoassay, we identified original content of metalloproteinases in serum of patients with BC, and after two weeks of the surgical treatment.

Differences between original serum levels of MMP-2 and MMP-7 and after surgical treatment of BC were within statistical error. MMP-9 in serum of patients with $\mathrm{BC}$ after treatment was significantly higher comparing to the original. The frequency of increasing the concentration of MMP-2 was $48.9 \%$, while value of the absolute increase was $58.7 \pm 9.3 \mathrm{ng} / \mathrm{ml}$, value of the absolute reduction was averagely $44.5 \pm 9.3 \mathrm{ng} / \mathrm{ml}$. Thus, in two weeks after the surgical treatment, the concentration of MMP- 2 in serum decreased averagely on $15.3 \%$ from the initial concentration approximately in half of the patients. It was found that the magnitude of the decline of MMP-2 after surgical treatment was proportional to the initial value of MMP-2, it means that marked decrease of MMP-2 concentration was found in patients with initially high level of MMP-2 $(r=0.44$; $p=0.037$ ). Twelve of 25 patients with BC had increased levels of MMP-7 in serum after treatment, the average 
level of increase was $19.2 \pm 7.5 \%$. In 13 of 25 patients, the average level of reduction of MMP-7 was $14.8 \pm$ $2.9 \%$. Thirty-four of 40 patients with BC had increased levels of MMP-9 in the serum after treatment. The average value of the enzyme's increasing was $68.6 \pm 11.3 \%$, and the average value of its reduction in six patients was $28.5 \pm 7.6 \%$. The more reduction matched to the bigger initial concentration of MMP-9 in serum ( $r=0.77 ; p=0.07)$, while the magnitude of MMP-9 increasing was not related to its initial concentration. A direct correlation between initial values of MMP-2 and MMP-9 in serum of patients with BC was detected only in the case of Stage I of oncological process $(r=0.83 ; p=0.01)$. With further progression of the disease, this dependence was not revealed. Values of MMP-2, MMP-7, and MMP-9 in the serum of patients with $\mathrm{BC}$ after treatment had not been linked to any correlation relationship. Connection between original content of MMP-2, MMP-7, and MMP-9 in the serum with age and reproductive status was not established (see Table 1).

Table 1

Concentrations of MMP-2, MMP-7, and MMP-9 in the Serum of Patients With BC Before and After Surgery

\begin{tabular}{lllll}
\hline $\begin{array}{l}\text { MMP's concentration before } \\
\text { and after treatment }\end{array}$ & $N$ & $M \pm m(\mathrm{Ng} / \mathrm{ml})$ & Limits of variation & $p$ (Before and after treatment) \\
\hline MMP-2 before & 45 & $244 \pm 9.0$ & $151-389$ & $>0.05$ \\
MMP-2 after & 45 & $253 \pm 8.0$ & $153-361$ & $>0.05$ \\
MMP-7 before & 25 & $4.5 \pm 0.3$ & $1.9-9.4$ & \\
MMP-7 after & 25 & $4.4 \pm 0.3$ & $2.8-11.0$ & $<0.0003$ \\
MMP-9 before & 40 & $234 \pm 14.3$ & $87-446$ & $136-847$ \\
MMP-9 after & 40 & $327 \pm 21.7$ & & \\
\hline
\end{tabular}

There was a significant increase of the concentration of MMP-2 and MMP-7 in tumors comparing to histologically unchanged breast tissue from $91.1 \%$ to $78.6 \%$, respectively. Elevated level of MMP-9 was found out in 59\% of patients, but this increase was not statistically significant. Correlation dependence of the content of metalloproteinases $-2,-7$, and -9 in unchanged tissue and primary tumor of breast we have not identified. To evaluate the clinical significance of the markers, we analyzed the possible relationship of the results to the main clinical and morphological features of the disease. The content of MMP-2 in primary tumor increased proportionally to the age of patients with $\mathrm{BC}$, and also in case of features that characterize clinically unfavorable prognosis. At the same time, the content of MMP-7 and MMP-9 was not associated with age of patients. In analyzing the concentration of metalloproteinases $-2,-7$, and -9 , types of tumor in $\mathrm{BC}$ patients with noting the reproductive function, we also did not find any significant differences. However, the highest level of MMP-2 was found in postmenopausal women. We did not find any significant correlation between the content of metalloproteinases $-2,-7$, and -9 tumor types in patients with $\mathrm{BC}$ and stage of disease. However, the highest median of MMP-2 in BC patients was at Stage I of disease. The highest median of metalloproteinases -2, -7, and -9 concentration was found in patients with multiple metastases in regional lymph nodes. However, the differences were not statistically significant. Significant correlation between the content of metalloproteinases -2 and -7 and degree of malignancy was not found. At the same time, the content of MMP-9 in patients with $\mathrm{BC}$ significantly increases with the degree of malignancy, which means that high concentrations of MMP-9 has unfavorable prognostic value. Correlation between the content of metalloproteinases $-2,-7$, and -9 with the largest sizes of tumor in patients has not been established. At the same time, analysis of variance showed significant increase of MMP-2 in the primary tumor in patients with a maximum size of the neoplasm. Median 
of MMP-7 and MMP-9 were highest in patients with the tumor's size more than $4.0 \mathrm{~cm}$, but the differences are not significant. No association was found between metalloproteinases $-2,-7$, and -9 and localization of neoplastic process. It was found an increased content of MMP-2 in case of presence sex steroid receptors (ER and PR). But higher levels of MMP-7 and MMP-9 were found in breast tumors that do not contain ER and PR, and in the case of detection HER-2/neu expression (see Table 2).

Table 2

Concentration of MMP-2, MMP-7, MMP-9 in BC Patients Including Expression ER, PR, and HER-2/NEU

\begin{tabular}{|c|c|c|c|c|c|c|}
\hline \multirow{2}{*}{$\begin{array}{l}\text { Receptoral } \\
\text { the tumor }\end{array}$} & \multirow{2}{*}{$\bar{N}$} & $\begin{array}{c}\text { MMP -2 } \\
\text { (U/mg of protein) }\end{array}$ & \multicolumn{2}{|c|}{$\begin{array}{c}\text { MMP-7 } \\
\text { (U/mg of protein) }\end{array}$} & \multicolumn{2}{|c|}{$\begin{array}{c}\text { MMP-9 } \\
\text { (U/mg of protein) }\end{array}$} \\
\hline & & Median (Quartiles) & $N$ & Median (Quartiles) & $N$ & Median (Quartiles) \\
\hline ER- & 11 & $\begin{array}{l}36.9 \\
(22.4-36.9)\end{array}$ & 5 & $\begin{array}{l}1.8^{*} \\
(1.3-4.1)\end{array}$ & 10 & $\begin{array}{l}24.0^{*} \\
(18.6-80)\end{array}$ \\
\hline ER+ & 33 & $\begin{array}{l}42.4 \\
(26.4-61.4)\end{array}$ & 19 & $\begin{array}{l}0.6^{* *} \\
(0.3-1.4)\end{array}$ & 29 & $\begin{array}{l}3.9^{* *} \\
(0-11.5)\end{array}$ \\
\hline PR- & 18 & $\begin{array}{l}31.7^{*} \\
(22.4-45.6)\end{array}$ & 10 & $\begin{array}{l}1.1 \\
(0.6-1.8)\end{array}$ & 16 & $\begin{array}{l}18.4 \\
(0.3-28.6)\end{array}$ \\
\hline $\mathrm{PR}+$ & 26 & $\begin{array}{l}46.2^{* *} \\
(32.8-68.1)\end{array}$ & 14 & $\begin{array}{l}0.7 \\
(0.3-1.4)\end{array}$ & 23 & $\begin{array}{l}4.7 \\
(0-11.9)\end{array}$ \\
\hline HER-2/neu- & 39 & $\begin{array}{l}41.3 \\
(26.3-56.4)\end{array}$ & 22 & $\begin{array}{l}0.7 \\
(0.4-1.6)\end{array}$ & 35 & $\begin{array}{l}7.6 \\
(0-19.6)\end{array}$ \\
\hline HER-2/neu+ & 5 & $\begin{array}{l}40.1 \\
(22.4-64.0)\end{array}$ & 2 & $\begin{array}{l}2.6 \\
(1-4.1)\end{array}$ & 4 & $\begin{array}{l}12.8 \\
(5.8-16.4)\end{array}$ \\
\hline
\end{tabular}

These all indicate the existence of a definite connection between the content of metalloproteinases $-2,-7$, and -9 types and tumor's receptor status in BC patients. Thus, the content of MMP-7 and MMP-9 was significantly higher in the prognostically unfavorable receptor status.

It was proved that patients with Stage III of BC had highest initial content of MMP-2 in the serum (see Table 3) and after surgical treatment, the decrease of MMP-2 was the lowest. Thus, the concentration of MMP-2 in the serum reflects the stage of disease and suggests that higher concentrations of MMP-2 in serum clinically unfavorable.

Table 3

The Concentrations of MMP-2, MMP-7, and MMP-9 in the Serum of Patients With BC Based on the Stage of the Disease

\begin{tabular}{llll}
\hline Stage of BC & I & II & III \\
\hline MMP-2 $(\mathrm{Ng} / \mathrm{ml})$ & $229 \pm 18.8^{*}(10)$ & $235 \pm 12.3^{*}(7)$ & $280 \pm 14.8^{* *}(8)$ \\
$M \pm m(N)$ & $3.8 \pm 0.1(24)$ & $4.7 \pm 0.6(4)$ & $4.6 \pm 0.2(21)$ \\
MMP-7 $(\mathrm{Ng} / \mathrm{ml})$ & $217 \pm 24.3(11)$ & $254 \pm 22.7(14)$ & $210 \pm 21.9(11)$ \\
MMP-9 $(\mathrm{Ng} / \mathrm{ml})$ & &
\end{tabular}

Note. $p<0.05$.

The original content of the marker MMP-7 in serum of patients with BC was not associated with the stage of disease. Frequency of MMP-7 reduction increased with the stage of disease from $40 \%$ in Stage I to $46.2 \%$ in Stage II, and to $71.4 \%$ in Stage III $(p=0.4)$. Thus, in patients with Stage III, post-treatment's reduction of MMP-7 was detected more frequently and it was more intense than in patients with stages II and I. It was found 
that in patients with Stage I, the original content of MMP-2 in serum was in direct proportion to the concentration of MMP-9 $(r=0.83 ; p=0.011)$. However, at Stage II or III, this dependence was broken.

Patients with Stage II had significant correlation between initial MMP-2 and MMP-7 $(r=0.93$; $p=0.0001$ ), but in patients with stages I and III, this dependence was absent. Thus, the original content of MMPs in serum of patients with $\mathrm{BC}$, reflects the prevalence of tumor process and may be a useful marker in the refinement of the disease prognosis. The original content of all studied proteases was not related to the criteria $\mathrm{T}$ and N. The highest frequency of the relative reduction of MMP-2 and MMP-7 was found in patients with multiple regional metastases ( $75 \%$ and $80 \%$, respectively), in patients with solitary metastases $(35.7 \%$ and $40 \%$ ), and in patients without metastases $(52.2 \%$ and $46.7 \%)$. The greatest increase of the initial content of MMP-2 in the serum of patients with BC was found in case of tumor's wide spreading (T4 N2-3). Significantly, lower initial content of MMP-9 detected in the serum of patients with low-differentiated BC $(167 \pm 31.2 \mathrm{ng} / \mathrm{ml})$, comparing with moderately differentiated $(250 \pm 27.4 \mathrm{ng} / \mathrm{ml})(p<0.05)$. Connections between the initial concentration of MMP-2, MMP-7 in serum of patients with BC, as well as the frequency and magnitude of these markers' relative decrease with the degree of tumor's malignancy was not detected. An association between the initial content of studied enzymes in the serum of patients with $\mathrm{BC}$ and the presence of tumor emboli in blood vessels of the tumor was not found $(p>0.05)$. After surgical treatment in an unfavorable group of patients with tumor emboli, the reduction of MMP-2 and, in particular, MMP-7, was often observed. Also, we have found the relative increase of MMP-9 in the serum of patients with tumor emboli. After surgical removal of the primary breast tumor, we detected a significant increase of only MMP-9 comparing to baseline $(p<0.0003)$. The lowest initial content of MMP-9 in the serum was found in patients with low-differentiated tumors $(p=0.04)$, high initial concentrations of MMP-2 have been identified in patients with Stage III, which may be clinically unfavorable sign. The results of the research show us that the concentration of metalloproteinases in serum of BC patients determined before surgical treatment, reflects the prevalence of oncological process. We believe that it is necessary to analyze the concentration of MMP in serum and tissues at the same time and also examine the content of endogenous inhibitors in the same patients.

\section{Conclusion}

We diagnosed a significant increase of MMP-2, MMP-7, and MMP-9 in tissues of patients with BC compared with normal tissues of the breast. Also, we have found correlation between increasing level of MMPs and sex hormone receptors and protein HER-2/neu. Thus, we can say that MMP-2, MMP-7, and MMP-9 totally increased in case of BC at the early stages, and their connection with protein HER-2/neu can tell us about their importance in the tumor's growth. We consider that if it would be possible to control the increase of MMPs, we would be able to decrease tumor's development and its growth, but of course we need additional research. In spite of this, even now we can prove that MMPs can help us as early biomarkers of BC. In future, we believe that all three metalloproteinases, after additional research, can be considered as potential biomarkers of another neoplastic lesions and possible metastasis' prevention, but there are questions that require further study.

\section{References}

Huang, L., Xu, A. M., \& Peng, Q. (2015). CD147 and MMP-9 expressions in type II/III adenocarcinoma of esophagogastric junction and their clinicopathological significances. International Journal of Clinical Experimental Pathology, 8(2), 1929-1937. 
Ito, Y., Ishiguro, H., Kobayashi, N., Hasumi, H., Watanabe, M., Yao, M., \& Uemura, H. (2015). Adipocyte-derived monocyte chemotactic protein-1 (MCP-1) promotes prostate cancer progression through the induction of MMP-2 activity. The Prostate, 75(10), 1009-1019.

Kuhn, E., Reis, A., Campagnoli, E. B., Chibinski, A. C., Carrilho, M. R., \& Wambier, D. S. (2005). Effect of sealing infected dentin with glass ionomer cement on the abundance and localization of MMP-2, MMP-8, and MMP-9 in young permanent molars. International Journal of Paediatric Dentistry. doi: 10.1111/ipd.12167

Radisky, E. S., \& Radisky, D. C. (2015). Matrix metalloproteinases as drivers and therapeutic targets in breast cancer. Frontiers in Bioscience (Landmark Edition), 1(20), 1144-1163.

Xu, X., Chen, L., Xu, B., Xie, Q., Sun, M., Deng, X., ... Jiang, J. (2015). Increased MT2-MMP expression in gastric cancer patients is associated with poor prognosis. International Journal of Clinical Experimental Pathology, 8(2), 1985-1990. 